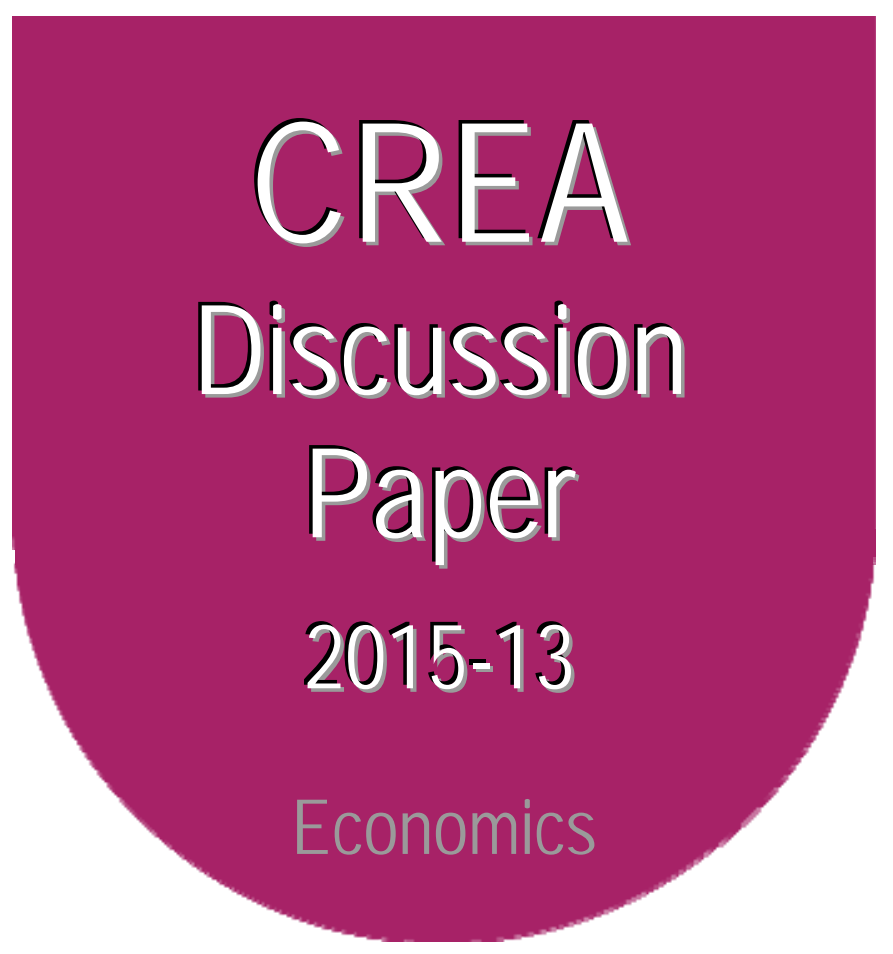

Center for Research in Economics and Management University of Luxembourg

\title{
Does eliminating international profit shifting increase tax revenue in high-tax countries?
}

available online : http://wwwfr.uni.Iu/recherche/fdef/crea/publications2/discussion_papers

Patrice Pieretti, CREA, Université du Luxembourg Giuseppe Pulina, CREA, Université du Luxembourg

September, 2015

For editorial correspondence, please contact: crea@uni.lu

University of Luxembourg

Faculty of Law, Economics and Finance $162 \mathrm{~A}$, avenue de la Faïencerie

L-1511 Luxembourg 


\title{
Does eliminating international profit shifting
}

\author{
increase tax revenue in high-tax countries?
}

\author{
Patrice PIERETTI * , Giuseppe PULINA ${ }^{\dagger}$
}

\begin{abstract}
We analyze under which conditions initiatives intended to eliminate profit shifting (such as the OECD BEPS action plan) can be successful given that these actions may induce multinational companies to relocate activities in low-tax countries. We demonstrate that removing tax-motivated profit shifting increases tax revenue in the onshore region if the low-tax jurisdiction is not too efficient in providing attractive infrastructure. This result is more likely to be obtained when the high-tax country is able to counter international activity shifting by competing in infrastructure with the tax haven rather than being passive.
\end{abstract}

JEL classification: F21, F23, H25, H26.

Keywords: BEPS, Profit shifting, Activity shifting, Tax havens, Multinational firms.

\footnotetext{
*University of Luxembourg, CREA

${ }^{\dagger}$ University of Luxembourg, CREA
} 


\section{Introduction}

In recent years there has been growing concern about aggressive tax avoidance by multinationals corporations (MNCs). In particular, MNCs are accused of paying virtually no taxes in the places where they operate by shifting profit to low-tax jurisdictions. These facts have clearly been documented in the recent literature (e.g. Desai et al., 2006a, Desai et al., 2006b, Huizinga \& Laeven, 2008 and Heckemeyer \& Overesch, 2013). Accordingly, the OECD launched in 2013 an initiative against base erosion and profit shifting (BEPS - OECD, 2013a , OECD, 2013b and OECD, 2014). This initiative, consisting in a 15-action plan, is intended to facilitate intergovernmental cooperation regarding taxation of multinational corporations. More specifically, the aim is to require that profits are taxed where economic activities and value creation occur. In other words, the focus is on artificial profit shifting for tax purposes and not on tax competition per se. In a recent interview, ${ }^{1}$ the head of OECD tax policy, told Fairfax Media that BEPS would "put an end to harmful tax competition, but not to tax competition". He also added that "some countries might move to be more attractive by reducing their rates. We think that's fine".

In reality, pure profit shifting is not the only way companies can lower their tax liabilities. They can benefit from low taxation by shifting real activities abroad if

\footnotetext{
${ }^{1}$ Sydney Morning Herald, November 14, 2014.
} 
the territorial taxation system, ${ }^{2}$ currently used by the majority of OECD countries, applies.

However, low taxes are not always enough to attract foreign firms. According to Dharmapala (2008) and Dharmapala \& Hines (2009), havens tend to have relatively sophisticated infrastructure ${ }^{3}$ and Gonzalez \& Schipke (2011, p.45) observe that "strong regulations that inspire confidence are a crucial factor" to attract foreign businesses. It follows that, physical and institutional infrastructure together with low taxation are essential to host foreign activities.

In a recent article, The Economist explains that "to avoid the perception of tax-dodging, some firms are starting to shift executives and head-office functions to their new domiciles" and that "America is starting to lose not just tax revenues but jobs too". Consequently, to lower their tax burdens and to avoid the perception of pure profit shifting MNCs begin to shift part of their real activity to low-tax jurisdictions (The Economist, 2015).

While activity shifting does not infringe the ongoing anti tax planning regulation, it still remains a form of base erosion from the point of view of high-tax countries, as pointed out by Hines (2014).

\footnotetext{
${ }^{2}$ According to this regime, multinationals are not taxed at home on their foreign income.

${ }^{3}$ Infrastructure can take various forms like telecommunications and transportation infrastructure, universities and public R\&D investment but also governance infrastructure like property rights enforcement, capital market regulations and more generally attractive laws and regulations.
} 
The following questions then arise. Do international anti-profit shifting regulations encourage tax havens to intensify their attractiveness to foreign substance based investments? In this case, will tax havens be capable to provide better attractive infrastructure? Could this induce multinational corporations (MNCs) to engage more in international activity shifting? Is it then conceivable that BEPS initiatives could fail?

This paper develops a simple model to analyze under which conditions initiatives intended to eliminate profit shifting can be successful given that these actions may induce relocation of substance based activities. The model demonstrates that the removal of tax-motivated profit shifting increases tax revenue in the onshore region if the low-tax jurisdiction is not too efficient in providing attractive infrastructure. This result is more likely to be obtained when the high-tax country is able to counter international activity shifting by competing in infrastructure with the tax haven rather than being passive.

Finally, we demonstrate that base erosion and onshore tax revenue are not necessarily affected in the same way by the elimination of profit shifting. More precisely, the eradication of profit shifting can increase tax revenue while not reducing base erosion.

The next section presents the basic model. In section 3, we assume that profit shifting can be eliminated. Section 4 compares tax revenue before and after the 
removal of profit shifting. Section 5 extends the model to the case of infrastructure competition between high and low tax jurisdictions. Section 6 concludes.

\section{The model set-up}

We consider a world economy with two countries, a large high-tax country $H$ and a small tax haven $F$. MNCs are located in $H$, each having one unit of capital that generates a profit $\Pi_{H}=q+\delta$. The fraction $q$ results from firm specific productivity, whereas $\delta$ is the output fraction that depends on the amount of infrastructure provided in the home country. For convenience and without loss of generality, we set $q=1$ so that $\Pi_{H}=1+\delta$.

The representative MNC contemplates the possibility of shifting part of its capital to the tax haven in order to set up a substance-based activity and/or the possibility of offshoring, through a special purpose entity, part of its profit generated in $H$.

Let $\theta$ denote the fraction of capital moved ${ }^{4}$ to the tax haven $F$ for setting up a substance-based activity and $\theta_{p}$ the portion of the profit $\Pi_{H}$ that is merely shifted offshore.

Following Johannesen (2010) and Haufler \& Schjelderup (2000), we consider that profit and capital shifting entail moving costs. We assume that the cost of

\footnotetext{
${ }^{4}$ In this case, the profit generated at home would be $(1-\theta) \Pi_{H}$.
} 
activity shifting increases with the amount of offshored capital, ${ }^{5}$ while we suppose that the cost of profit shifting increases with the parameter $\theta_{p}$ that can be viewed as the share of concealed tax-base. The latter assumption that is similar to Haufler \& Schjelderup (2000) results from the fact that additional efforts are necessary to increase income concealment and that the probability of being detected increases with the degree of concealment.

We introduce convex costs for profit and activity shifting. The corresponding cost functions are respectively $\frac{1}{2} \theta_{p}^{2}$ and $\frac{\alpha}{2} \theta^{2}$. Note that it is common practice to use convex functions in two-country models (Haufler \& Schjelderup, 2000 and Stöwhase, 2005) that try to capture the costly effort of MNCs to avoid home taxation. The parameter $\alpha \in R^{+}$accounts for the difficulty to shift activity relative to profit shifting. Because profit shifting can be achieved virtually, we can assume that shifting activities is at least as difficult. In other terms, we assume that $\alpha \geq 1{ }^{6}$

The onshore country taxes corporate income at a rate $t \in\left[0, \Pi_{H}\right]$, while the tax haven $F$ does not levy a corporate tax. Generally, it is not very costly to offer tax sheltering services, but public investments are required to guarantee a

\footnotetext{
${ }^{5}$ Offshoring real activities requires costs resulting from building or renting the business premises as well as from moving the starting material, etc.

${ }^{6}$ If $0<\alpha<1$, activity shifting would be relatively easier to achieve. This would make the removal of profit shifting less able to augment tax revenues in high tax countries.
} 
favorable environment to attract foreign firms that invest in substance based activities. Consequently, let $G$ be the amount of public infrastructure provided by the tax haven. Let us assume that $G$ units of infrastructure are needed to generate $G$ units of net output. Additionally, we suppose that the cost of infrastructure provision increases at an increasing rate due to diminishing returns to scale. We thus introduce a quadratic function $\frac{\beta}{2} G^{2}$, where $\beta$ measures the efficiency of the tax haven in producing attractive infrastructure. Note that a lower value of $\beta$ indicates higher efficiency in providing $G$.

The tax haven levies fees for the tax planning and infrastructure services it provides. Accordingly, a fee $f_{p}$ is charged on one unit of profit shifted abroad and a fee $f$ is levied on one unit of capital moved to the tax haven.

By analogy to what we did above, capital shifted to the tax haven yields a net output depending on both firm and jurisdictional characteristics. It follows that a fraction $\theta$ of capital moved to the tax haven generates a profit $\Pi_{F}=\theta+\theta G$.

We can now write the following profit equation of the representative MNC

$$
V=\left(1-\theta_{p}-\theta\right)\left(\Pi_{H}-t\right)+\theta_{p}\left(\Pi_{H}-f_{p}\right)+\theta\left(\Pi_{F}-f\right)-\frac{1}{2} \theta_{p}^{2}-\frac{\alpha}{2} \theta^{2} .
$$

The first term of (1) represents the net (of corporate tax) income generated at home (country $H$ ). The second and third terms refer to the net income resulting respectively from profit and activity shifting. Finally, the two last terms, are respectively the cost of offshoring profit and activity. 
A two-stage game is considered. First, country $H$ sets the corporate tax rate $t$ while the tax haven $F$ sets the fees $f_{p}$ and $f$ and the infrastructure provision G. These last choices are made simultaneously and non-cooperatively by the jurisdictions. Finally, the MNC decides on $\theta_{p}$ and $\theta$, namely, the shares of profit and activity shifting respectively.

\subsection{Reallocation of taxable income and activity shifting}

In this section, we analyze how a representative MNC located in country $H$ decides on the mix of taxable income allocation and activity shifting. Consequently, after having done some substitutions in (1), we assume that the MNC maximizes $V\left(\theta_{p}, \theta\right)$ with respect to $\theta_{p}$ and $\theta$.

$V\left(\theta_{p}, \theta\right)=\left(1-\theta_{p}-\theta\right)(1+\delta-t)+\theta_{p}\left(1+\delta-f_{p}\right)+\theta(1+G-f)-\frac{1}{2} \theta_{p}^{2}-\frac{\alpha}{2} \theta^{2}$,

subject to

$$
\begin{aligned}
\theta_{p}+\theta & \leq 1, \\
\theta_{p} & \geq 0, \\
\theta & \geq 0 .
\end{aligned}
$$


The first order conditions resulting from the profit maximization yield

$$
\begin{aligned}
\theta_{p} & =t-f_{p}, \\
\theta & =\frac{t-f+G-\delta}{\alpha} .
\end{aligned}
$$

Equation 4 highlights that a multinational company can have an incentive to invest in real offshore activities even if the home country provides more attractive infrastructure relative to the tax haven $(\delta>G)$. A sufficient condition for the occurrence of activity shifting is that the tax gain $t-f$ has to be high enough. Indeed, it is easy to check that $\theta>0$ if $t-f>\delta-G$.

\subsection{The governments' decisions}

We assume that the onshore country sets the corporate tax rate that maximizes its tax revenue $T$ relative to the tax rate $t$. The tax haven decides on the fees $f_{p}$ and $f$ and the infrastructure expenditure $G$ that maximize its net revenue $W$. The optimization problems are

$$
\begin{array}{ll}
\max _{t} & T=t\left(1-\theta_{p}-\theta\right), \\
\max _{f_{p}, f, G} & W=f_{p} \theta_{p}+f \theta-\frac{\beta}{2} G^{2} .
\end{array}
$$

subject to the non negativity conditions (1a)-(1c).

While maximizing their respective objectives, the governments anticipate the 
MNC's behavior. Therefore, taking account of (3) and (4), the best response of the onshore jurisdiction becomes

$$
t^{b r}=\frac{\alpha\left(1+f_{p}\right)+f-(G-\delta)}{2(1+\alpha)} .
$$

The onshore country's best tax response $t$ is increasing in the tax haven's fees and decreasing in the infrastructure provision. Intuitively, the onshore country has an incentive to increase (decrease) its tax rate any time the tax haven decreases (increases) its attractiveness.

Accordingly, the best responses of the tax haven are

$$
\begin{aligned}
f_{p}^{b r} & =\frac{t}{2} \\
f^{b r} & =\frac{\alpha \beta(t-\delta)}{2 \alpha \beta-1} \\
G^{b r} & =\frac{t-\delta}{2 \alpha \beta-1} .
\end{aligned}
$$

The second order conditions are always satisfied for $\alpha \beta>\frac{1}{2}$. ${ }^{7}$ Consequently, we assume that activity shifting and providing attractive infrastructure are jointly difficult enough. Note that when the onshore economy increases its corporate tax rate, the tax haven's best response is to raise its infrastructure provision and the fees of the services it provides. The reason is because higher taxation encourages

\footnotetext{
${ }^{7}$ It is easy to check that $\frac{\partial^{2} T}{\partial t^{2}}<0, \frac{\partial^{2} W}{\partial f^{2}}<0, \frac{\partial^{2} W}{\partial f_{p}^{2}}<0, \frac{\partial^{2} W}{\partial G^{2}}<0$ and $\frac{\partial^{2} W}{\partial f^{2}} \cdot \frac{\partial^{2} W}{\partial G^{2}}-\left(\frac{\partial^{2} W}{\partial f \partial G}\right)^{2}>0$ if $\alpha \beta>\frac{1}{2}$.
} 
profit and activity shifting by MNCs. Accordingly, the tax haven has an incentive to capture a part of firms' resulting tax gains by increasing its fees.

Solving the system of the above best responses, we obtain the following equilibrium values

$$
\begin{aligned}
t^{*} & =\frac{2 \alpha(2 \alpha \beta-1+\beta \delta)}{2(3 \alpha \beta-1)+3 \alpha(2 \alpha \beta-1)}, \\
f_{p}^{*} & =\frac{\alpha(2 \alpha \beta-1+\beta \delta)}{2(3 \alpha \beta-1)+3 \alpha(2 \alpha \beta-1)}, \\
f^{*} & =\frac{\alpha \beta(2 \alpha-\delta(2+3 \alpha))}{2(3 \alpha \beta-1)+3 \alpha(2 \alpha \beta-1)}, \\
G^{*} & =\frac{2 \alpha-\delta(2+3 \alpha)}{2(3 \alpha \beta-1)+3 \alpha(2 \alpha \beta-1)} .
\end{aligned}
$$

An interior solution ${ }^{8}$ is guaranteed by the condition

$$
\alpha \beta>\frac{1}{2}
$$

The equilibrium shares of profit and activity shifting are

$$
\begin{aligned}
& \theta^{*}=\frac{\beta(2 \alpha-\delta(2+3 \alpha))}{2(3 \alpha \beta-1)+3 \alpha(2 \alpha \beta-1)}, \\
& \theta_{p}^{*}=\frac{\alpha(2 \alpha \beta-1+\beta \delta)}{2(3 \alpha \beta-1)+3 \alpha(2 \alpha \beta-1)} .
\end{aligned}
$$

The equilibrium tax revenue in the high-tax country is

$$
T^{*}=\frac{4 \alpha(1+\alpha)(2 \alpha \beta-1+\beta \delta)^{2}}{(2(3 \alpha \beta-1)+3 \alpha(2 \alpha \beta-1))^{2}} .
$$

\footnotetext{
${ }^{8}$ It follows that condition $1 a$ is not binding.
} 


\section{The elimination of profit shifting}

In this section, we use the above results to analyze how the elimination of profit shifting can affect tax revenues in the high-tax country $H$. In other words, we set $\theta_{p}=0$

The MNC's profit function becomes

$$
\widehat{V}=(1-\theta)(1+\delta-t)+\theta(1+G-f)-\frac{\alpha}{2} \theta^{2}
$$

Maximizing the profit function yields the equilibrium share of activity shifting

$$
\widehat{\theta}=\frac{t-f+G-\delta}{\alpha}
$$

The governments' best responses are

$$
\begin{aligned}
\widehat{t}_{b r} & =\frac{\alpha+f-(G-\delta)}{2}, \\
\widehat{f}_{b r} & =\frac{\alpha \beta(t-\delta)}{2 \alpha \beta-1} \\
\widehat{G}_{b r} & =\frac{t-\delta}{2 \alpha \beta-1}
\end{aligned}
$$

Solving the above equation system yields the following equilibrium variables

$$
\begin{aligned}
\widehat{t}^{*} & =\frac{\alpha(2 \alpha \beta-1+\beta \delta)}{3 \alpha \beta-1}, \\
\widehat{f}^{*} & =\frac{\alpha \beta(\alpha-\delta)}{3 \alpha \beta-1}, \\
\widehat{G}^{*} & =\frac{\alpha-\delta}{3 \alpha \beta-1} .
\end{aligned}
$$

These equilibrium variables are positive because of condition (5). 
The share of activity shifting becomes

$$
\widehat{\theta}^{*}=\frac{\beta(\alpha-\delta)}{3 \alpha \beta-1}
$$

Finally, the equilibrium tax revenue in the high-tax country equals

$$
\widehat{T}^{*}=\frac{\alpha(2 \alpha \beta-1+\beta \delta)^{2}}{(3 \alpha \beta-1)^{2}} .
$$

\section{The effectiveness of removing profit shifting}

In the following proposition we establish under which condition removing profit shifting can have an adverse effect on the tax revenue in the high tax country.

Proposition 1 The removal of profit shifting decreases the tax revenue in the high-tax country if the tax haven is efficient enough in providing attractive infrastructure to MNCs. However, this is less likely to occur the more it is costly to shift activities in the tax haven. Formally:

$$
\Delta T=\widehat{T}^{*}-T^{*}<0 \quad \text { if } \quad \beta<\widetilde{\beta},
$$

where

$$
\widetilde{\beta}=\frac{1}{\alpha}\left(\frac{1}{2}+\frac{1}{6 \sqrt{1+\alpha}}\right) \quad \text { and } \quad \frac{\partial \widetilde{\beta}}{\partial \alpha}<0
$$

Proof. Let us set

$$
\Delta T=A \cdot B,
$$


where

$$
\begin{aligned}
& A=\frac{\alpha^{2}(2 \alpha \beta-1+\beta \delta)^{2}}{(3 \alpha \beta-1)^{2}(6 \alpha \beta(1+\alpha)-(2+3 \alpha))^{2}}>0, \\
& B=36(1+\alpha) \alpha^{2} \beta^{2}-36(1+\alpha) \alpha \beta+8+9 \alpha .
\end{aligned}
$$

It follows that $\operatorname{sign}(\Delta T)=\operatorname{sign}(B)$. From (14), we see that $B$ is quadratic in $\beta$. Solving $B(\beta)=0$ relative to $\beta$ yields two distinct positive roots ${ }^{9}$, but only the highest value $\widetilde{\beta}$ of both is relevant if we impose condition (5) that guarantees the existence of an interior solution. So, we conclude that

$$
\Delta T= \begin{cases}\leq 0 & \beta \leq \widetilde{\beta} \\ >0 & \text { otherwise. }\end{cases}
$$

Intuitively, the removal of profit shifting makes MNCs more captive, which induces the onshore region to increase its corporate tax rate $t$. This entices the tax haven to invest in attractive infrastructure designed to encourage activity shifting by MNCs which increases $\theta$. If the elimination of profit shifting increases relatively more activity shifting than corporate taxation, tax revenue will decrease. Consequently, a successful elimination of profit shifting translates into higher onshore

$$
{ }^{9} \widetilde{\beta}=\frac{1}{\alpha}\left(\frac{1}{2}+\frac{1}{6 \sqrt{1+\alpha}}\right)>0 \text { and } \widetilde{\widetilde{\beta}}=\frac{1}{\alpha}\left(\frac{1}{2}-\frac{1}{6 \sqrt{1+\alpha}}\right)>0 .
$$


tax revenues if tax havens are unable to increase sufficiently their attractiveness to foreign real business.

\section{Infrastructure competition}

In this section, we assume that the high-tax region tries to counter international activity shifting by competing in infrastructure with the tax haven. One important aspect is to check the robustness of the above conclusions by endogenizing the infrastructure choice of the onshore country.

In the following, we limit ourselves to the main results and the computations are relegated to Appendix A.

As we did it for the tax haven we assume that $\delta$ units of infrastructure are needed to generate $\delta$ units of net output in the onshore economy. Hence, $\delta$ accounts for both the infrastructure provision and the resulting output that accrues to home investing firms. Once again, we assume that the cost of infrastructure provision is given by an increasing convex function $\frac{\delta^{2}}{2}$.

Now the onshore country is supposed to choose the corporate tax rate $t$ and the amount $\delta$. Consequently, the problem of the high-tax country becomes ${ }^{10}$

$$
\max _{t, \delta} \quad W_{h}=t\left(1-\theta_{p}-\theta\right)-\frac{\delta^{2}}{2}
$$

\footnotetext{
${ }^{10} \mathrm{It}$ is easy to check that the following second order conditions are verified: $\frac{\partial^{2} W_{h}}{\partial t^{2}}<0, \frac{\partial^{2} W_{h}}{\partial \delta^{2}}<0$ and $\frac{\partial^{2} W_{h}}{\partial t^{2}} \cdot \frac{\partial^{2} W_{h}}{\partial \delta^{2}}-\left(\frac{\partial^{2} W_{h}}{\partial t \partial \delta}\right)^{2}>0$, given that $\alpha \geq 1$.
} 
As already assumed in the previous sections, the tax haven is supposed to decide on the fees $f_{p}$ and $f$ and the infrastructure expenditure $G$. In the appendix we solve the game between the onshore and offshore jurisdictions with and without profit shifting. The following results can then be highlighted. ${ }^{11}$

First, we show (see Appendix A) that the onshore economy can provide a higher equilibrium amount of infrastructure than the tax haven $\left(\delta^{* *}>G^{* *}\right.$ and $\left.\widehat{\delta}^{* *}>\widehat{G}^{* *}\right)$ if $\beta>\frac{1}{2}$. Notwithstanding this case, the onshore economy is not able to prevent activity shifting $\left(\theta^{* *}>0\right.$ and $\left.\widehat{\theta}^{* *}>0\right)$. As we explained in a previous section, this is the case because the relative tax advantage provided by the tax haven is high enough.

Second, in case of a removal of profit shifting the welfare of the high-tax economy will not unambiguously increase. Indeed, the elimination of tax planning reduces the onshore welfare (the tax revenue net of the cost of infrastructure provision) if the low-tax jurisdiction is efficient enough in providing attractive infrastructure $\left(\widehat{W}_{h}^{* *}<W_{h}^{* *}\right.$ if $\left.\beta<\widetilde{\beta}^{\prime}\right)$. However, this case is more likely to occur when the the high tax economy does not compete in infrastructure provision, given that $\widetilde{\beta^{\prime}}<\widetilde{\beta}$ as we prove in Appendix A.

Proposition 2 When the high tax jurisdiction uses infrastructure provision strategically, the removal of profit shifting can reduce the welfare in the high-tax economy

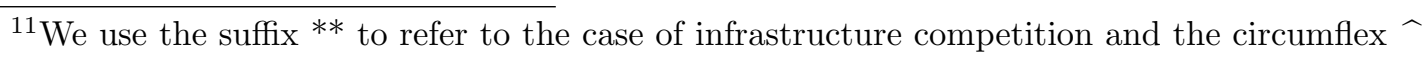
is used in the absence of profit shifting.
} 
if the tax haven is efficient enough in providing attractive infrastructure. However, this effect is more likely to occur when the high tax jurisdiction considers infrastructure provision as exogenously given. Formally

$$
\Delta W_{h}=\widehat{W}_{h}^{* *}-W_{h}^{* *}<0 \text { if } \beta<\widetilde{\beta}^{\prime} \quad \text { with } \quad \widetilde{\beta}^{\prime}<\widetilde{\beta}
$$

Proof. In the Appendix A.

The underlying intuition is the same as explained above. If the elimination of profit shifting increases relatively more activity shifting than corporate taxation, tax revenue will decrease.

The official debate about profit shifting is mainly focused on the concept of base erosion $(\mathcal{B})$. In our model, base erosion is given by the parameters $\theta_{p}$ and $\theta$, which stand respectively for the shares of profit and activity shifting. Consequently, the amount of base erosion with and without profit shifting (in case of infrastructure competition) is given by

$$
\begin{aligned}
& \mathcal{B}=\theta^{* *}+\theta_{p}^{* *}=\frac{\alpha(2 \alpha \beta-1)+2 \beta(\alpha-1)}{3 \alpha(2 \alpha \beta-1)+2 d}, \\
& \widehat{\mathcal{B}}=\widehat{\theta}^{* *}=\frac{\beta(\alpha-1)}{d} .
\end{aligned}
$$

Let us now check if base erosion and tax revenue losses incurred by high tax jurisdictions move in the same direction. To this end we consider the difference 
$\Delta \mathcal{B}=\widehat{\mathcal{B}}-\mathcal{B}$ given by the following expression.

$$
\Delta \mathcal{B}=\frac{\alpha(2 \alpha \beta-1)(1-2 \beta)}{d(3 \alpha(2 \alpha \beta-1)+2 d)}
$$

It follows that the removal of profit shifting induces base repatriation $(\Delta \mathcal{B}<0)$ if the tax haven is not efficient enough $\left(\beta>\frac{1}{2}\right)$ in providing attractive infrastructure. In this case, base repatriation implies increasing welfare in the high-tax jurisdiction because $\beta>\widetilde{\beta^{\prime}}$, given that $\frac{1}{2}>\widetilde{\beta^{\prime}} .{ }^{12}$ Note that a decrease in base erosion is sufficient to induce increased tax revenue but it is not a necessary condition. Indeed, if $\widetilde{\beta^{\prime}}<\beta<\frac{1}{2}$, the eradication of profit shifting increases tax revenue in the onshore economy even if base erosion increases. The intuition can be explained as follows.

When profit shifting is eliminated firms are more prone to higher taxation in their home country. As a reaction, the tax haven tries to encourage activity shifting by increasing its infrastructure provision. This can result in a higher outflow of taxable income such that base erosion increases but to a lesser extent than taxation resulting from the removal of profit shifting. This is precisely what happens when the efficiency parameter is comprised between $\widetilde{\beta^{\prime}}$ and $\frac{1}{2}$.

Proposition 3 Decreasing base erosion as a consequence of the removal of profit shifting is sufficient to induce increased tax revenue in the onshore economy. The reverse is not necessarily true. In particular, if $\widetilde{\beta^{\prime}}<\beta<\frac{1}{2}$, the eradication of

\footnotetext{
${ }^{12}$ Indeed, $\lim _{\alpha \rightarrow 1} \widetilde{\beta^{\prime}}=\frac{1}{2}$ and $\frac{\partial \widetilde{\beta}^{\prime}}{\partial \alpha} \leq 0, \forall \alpha>1$.
} 
profit shifting increases tax revenue in the onshore economy even if base erosion increases.

\section{Conclusions}

Base erosion through profit shifting is considered a serious problem since it potentially reduces tax revenue in onshore economies. In this context, the BEPS initiative, launched recently by the OECD (OECD, 2013a ,OECD, 2013b and OECD, 2014), should help eliminate profit shifting with the aim to increase onshore tax revenue.

This paper demonstrates that the effects of BEPS initiatives could be undermined. In fact, in the same vein as Hines (2014), we argue that anti tax-planning regulations can induce multinational firms to use other ways to mitigate their tax liabilities, like shifting real activities to tax havens. As a result, the removal of tax-motivated profit shifting increases tax revenue in the onshore region only if the low-tax jurisdiction is not too efficient in providing attractive infrastructure. Additionally, we highlight that the success of BEPS initiatives is more likely to occur if the high-tax country is able to counter international activity shifting by competing in infrastructure rather than being passive.

The recent BEPS initiative does not account for international activity transfers that could result from anti profit-shifting campaigns. However, we could witness 
the emergence of another form of base erosion that should deserve official scrutiny.

Finally, we highlight that fighting aggressive tax planning does not necessarily affect base erosion and onshore tax revenue in the same way. In particular, a possible eradication of profit shifting can increase tax revenue without the need to reduce base erosion.

\section{References}

Desai, M.A., Foley, C.F., \& Hines, J.R. 2006a. The demand for tax haven operations. Journal of Public Economics, 90, 513-531.

Desai, Mihir A., Foley, C. Fritz, \& Hines, James Jr. 2006b. A Multinational Perspective on Capital Structure Choice and Internal Capital Markets. The Journal of Finance, 59, 2451-2487.

Dharmapala, D. 2008. What problems and opportunities are created by tax havens? Oxford Review of Economic Policy, 24, 661-679.

Dharmapala, D., \& Hines, J.R. 2009. Which countries become tax havens? Journal of Public Economics, 93(9-10), 1058-1068.

Gonzalez, M., \& Schipke, A. 2011. Bankers on the Beach. Finance \& Development, 48(2), 42-45. 
Haufler, A., \& Schjelderup, G. 2000. Corporate tax systems and cross country profit shifting. Oxford economic papers, 52, 306-325.

Heckemeyer, J. H., \& Overesch, M. 2013. Multinationals' profit response to tax differentials: Effect size and shifting channels. ZEW Discussion Paper, 13-045.

Hines, J.R. 2014. Policy Forum: How Serious Is the Problem of Base Erosion and Profit Shifting? Canadian tax journal, 62, 443-454.

Huizinga, H., \& Laeven, L. 2008. International Profit Shifting Within European Multinationals. Journal of Public Economics, 92, 1164-1182.

Johannesen, N. 2010. Imperfect tax competition for profits, asymmetric equilibrium and beneficial tax havens. Journal of International Economics, 84, 253-264.

OECD. 2013a. Action Plan on Base Erosion and Profit Shifting. Paris: Organisation for Economic Cooperation and Development.

OECD. 2013b. Addressing Base Erosion and Profit Shifting. Paris: Organisation for Economic Cooperation and Development.

OECD. 2014. Explanatory Statement, OECD/G20 Base Erosion and Profit Shifting Project. Paris: Organisation for Economic Cooperation and Development. 
StöWHASE, S. 2005. Asymmetric capital tax competition with profit shifting. Journal of Economics, 85(2), 175-196.

The Economist. 2015. All my bags are packed - Corporate America's tax-driven exodus continues. The Economist, August 15th.

\section{Appendix A: the model with infrastructure com-}

\section{petition}

First we solve the game described in section 5 in the absence of profit shifting.

The resulting equilibrium variables are given as follows:

$$
\begin{aligned}
\widehat{t}^{* *} & =\frac{\alpha(2 \alpha \beta-1)}{d}, \\
\widehat{\delta}^{* *} & =\frac{2 \alpha \beta-1}{d}, \\
\widehat{G}^{* *} & =\frac{\alpha-1}{d}, \\
\widehat{f}^{* *} & =\alpha \beta \cdot \widehat{G}^{* *}, \\
\widehat{\theta}^{* *} & =\frac{\beta(\alpha-1)}{d},
\end{aligned}
$$

where $d=\beta(3 \alpha-1)-1>0 \quad$ since $\quad \alpha \geq 1$ and $\quad \alpha \beta>\frac{1}{2}$.

Note that $\widehat{\delta}^{* *}-\widehat{G}^{* *}=\alpha \frac{2 \beta-1}{d}$. Consequently, we see that $\widehat{\delta}^{* *}>\widehat{G}^{* *}$ when $\beta>\frac{1}{2}$.

In this case, the onshore economy provides more attractive infrastructure than the tax haven. 
The equilibrium tax revenue in the high-tax country is

$$
\widehat{W}_{h}^{* *}=\frac{(2 \alpha-1)(2 \alpha \beta-1)^{2}}{2 d^{2}}
$$

If we consider the game with the possibility of profit shifting, the game yields the following equilibrium results

$$
\begin{aligned}
t^{* *} & =\underbrace{\left(\frac{2 d}{3 \alpha(2 \alpha \beta-1)+2 d}\right)}_{<1} \widehat{t}^{* *}<\widehat{t}^{* *}, \\
\delta^{* *} & =\underbrace{\left(\frac{2 d}{3 \alpha(2 \alpha \beta-1)+2 d}\right)}_{<1} \widehat{\delta}^{* *}<\widehat{\delta}^{* *}, \\
G^{* *} & =\underbrace{\left(\frac{2 d}{3 \alpha(2 \alpha \beta-1)+2 d}\right)}_{<1} \widehat{G}^{* *}<\widehat{G}^{* *}, \\
f^{* *} & =\alpha \beta \cdot G^{* *}, \\
f_{p}^{* *} & =\frac{t^{* *}}{2} .
\end{aligned}
$$

The equilibrium levels of profit and activity shifting are

$$
\begin{aligned}
& \theta^{* *}=\frac{2 \beta(\alpha-1)}{3 \alpha(2 \alpha \beta-1)+2 d}, \\
& \theta_{p}^{* *}=\frac{\alpha(2 \alpha \beta-1)}{3 \alpha(2 \alpha \beta-1)+2 d} .
\end{aligned}
$$


The equilibrium tax revenue in the high-tax country is

$$
W_{h}^{* *}=\frac{2(2 \alpha(1+\alpha)-1)(2 \alpha \beta-1)^{2}}{(3 \alpha(2 \alpha \beta-1)+2 d)^{2}}
$$

Consequently it follows that

$$
\Delta W_{h}=\widehat{W}_{h}^{* *}-W_{h}^{* *}<0 \quad \text { if } \quad \beta<\widetilde{\beta}^{\prime}
$$

To provide a proof, first set $\Delta W_{h}=A^{\prime} \cdot B^{\prime}$, where

$$
\begin{aligned}
& A^{\prime}=\frac{1}{2} \frac{(2 \alpha \beta-1)^{2}}{d^{2}[3 \alpha(2 \alpha \beta-1)+2 d]^{2}}>0, \\
& B^{\prime}=4\left[4+9 \alpha\left(-2+\alpha+2 \alpha^{2}\right)\right] \alpha^{2} \beta^{2} \\
& \quad-4[3+\alpha(9 \alpha(1+2 \alpha))-17] \alpha \beta \\
& \quad+\alpha[\alpha(7+18 \alpha)-12] .
\end{aligned}
$$

It follows that $\operatorname{sign}\left(\Delta W_{h}\right)=\operatorname{sign}\left(B^{\prime}\right)$. From $(21)$, we see that $B^{\prime}$ is quadratic in $\beta$. Solving $B^{\prime}(\beta)=0$ relative to $\beta$ yields two distinct positive roots, ${ }^{13}$ but only the highest value $\widetilde{\beta^{\prime}}$ of both is relevant if we impose the condition (5) that guarantees the existence of an interior solution.

$$
\begin{gathered}
13 \widetilde{\beta^{\prime}}=\frac{\alpha(9 \alpha(1+2 \alpha)-17)+3\left(1+(\alpha-1) \sqrt{1+2 \alpha\left(-2+\alpha+2 \alpha^{2}\right)}\right)}{2 \alpha\left(4+9 \alpha\left(-2+\alpha+2 \alpha^{2}\right)\right)} \text { and } \\
\widetilde{\beta^{\prime}}=\frac{\alpha(-17+9 \alpha(1+2 \alpha))-3\left(-1+\sqrt{(-1+\alpha)^{2}\left(1+2 \alpha\left(-2+\alpha+2 \alpha^{2}\right)\right)}\right)}{2 \alpha\left(4+9 \alpha\left(-2+\alpha+2 \alpha^{2}\right)\right)}>0 .
\end{gathered}
$$


So, we conclude that

$$
\Delta W_{h}= \begin{cases}\leq 0 & \beta \leq \widetilde{\beta^{\prime}} \\ >0 & \text { otherwise }\end{cases}
$$

Recalling the threshold value $\widetilde{\beta}$, it follows that $\widetilde{\beta}>\widetilde{\beta}^{\prime}>0$ for finite values of $\alpha$ $(\alpha>1)$. The proof is derived from the following properties. The difference $\widetilde{\beta}-\widetilde{\beta}^{\prime}$ is strictly positive when $\alpha=1$ and tends to 0 when $\alpha \rightarrow+\infty$. In addition, we verify that $\frac{\partial \widetilde{\beta}}{\partial \alpha}<0$ and $\frac{\partial \widetilde{\beta^{\prime}}}{\partial \alpha}<0, \forall \alpha>1$. 